\title{
La mediación como política de bienestar ${ }^{1}$
}

\author{
The mediation as a welfare policy
}

Francisco Gorjón-Gómez ${ }^{2}$

Universidad Autónoma de Nuevo León, México

\begin{abstract}
RESUMEN
El presente artículo es parte de una secuencia de diversas investigaciones sustentadas en una LGAC dentro del programa de Doctorado de MASC, que tiene como objetivo central crear una cultura para el uso de los MSC. Representa la parte teórica del proyecto de investigación PAICYT 2019 denominado "Mediación camino al bienestar", dirigido a identificar el marco teórico del bienestar y de los MSC, por lo que se realizó una exegesis de la literatura vinculada al tema desde la perspectiva comparada, permitiéndonos llegar a conclusiones teóricas asertivas, por lo que la revisión efectuada en esta primera etapa cumplió su cometido, arribando a las siguientes conclusiones: La mediación es un catalizador de bienestar y de felicidad, genera estabilidad social. La mediación es hoy en día una vía para la paz. La mediación y los MSC se transforman y gestionan conflictos desde la óptica de los intereses y del bienestar subjetivo percibido sustentados ambos en la autonomía y el libre albedrio. Se propone invertir la generación de bienestar en razón de la lógica del bienestar subjetivo percibido, otorgándole un papel protagónico a las personas, pasando de ser un actor pasivo a un actor activo y de cómo desde su felicidad resuelven sus conflictos.
\end{abstract}

Palabras claves: Bienestar, bienestar subjetivo, bienestar subjetivo percibido, felicidad, mediación.

\section{ABSTRACT}

This article is part of a sequence of diverse research supported by an LGAC within the MASC PhD program, whose main objective is to create a culture for the use of MSCs. Representative of the theoretical part of the research project PAICYT 2019 called "Mediation path to well-being", aimed at identifying the theoretical framework of well-being and the MSC, for which an exegesis of the literature related to the subject was carried out from a comparative perspective, allowing us to reach assertive theoretical conclusions, so the review carried out in this first stage fulfilled its kite, reaching the following conclusions: Mediation is a catalyst for well-being and happiness, it generates social stability. Mediation is today a way to peace. Mediation and MSCs transform and manage conflicts from the perspective of interests and perceived subjective well-being, both supported by autonomy and free will. It is proposed to reverse the generation of well-being due to the logic of perceived subjective well-being, granting a leading role to people, going from being a passive actor to an active actor and how from their happiness they resolve their conflicts.

Keywords: Happiness, mediation, peace, perceived subjective well-being, subjective well-being, well-being.

Recibido: 26 de Octubre 2019 - Aceptado: 01 de Abril 2020 - Corregido: 30 de Abril 2020

Cómo referenciar este artículo:

Gorjón-Gómez, F. (2020). La mediación como política de bienestar. Politica Globalidad y Ciudadanía, 67-83. Recuperado de http://revpoliticas.uanl.mx/index.php/RPGyC/article/view/147

1 Artículo de investigación original derivado del proyecto: PAICYT 2019 "Mediación camino al bienestar".

2 Doctor por la Universidad Complutense de Madrid. Director del Doctorado en Métodos Alternos de Solución de Controversias de la Facultad de Derecho y Criminología de la Universidad Autónoma de Nuevo León. Email: fgorjon@hotmail.com 


\section{1.- INTRODUCCION}

Actualmente la mediación y los MSC se sitúan en un entorno diferente al de las políticas de bienestar social por lo que su alcance es limitado, situándose solo en la esfera de las políticas normativistas, ello representa un verdadero problema porque ante tal exclusión la sociedad la desconoce y no solo ello limita su evolución y operacionalización, ya que los métodos de culturización están restringidos, siendo necesario transitar a las políticas de bienestar que le darán visibilidad, promoción y gestión, pero principalmente utilidad en un entorno que procura la felicidad y la paz de las personas y no el control como sucede ahora por la limitación y la restricción que impone la norma.

Proponemos, entonces, en el marco de esta sinergia que la mediación se constituya en una política de bienestar social y salga del entorno de las políticas normativistas que hasta ahora la tienen limitada y han impedido con el paso de los lustros la culturización de la sociedad en el uso de los MSC y han limitado significativamente su operacionalización, teniendo un alcance mínimo y un insignificante impacto social.

Tradicionalmente las políticas de bienestar recaen su creación y ejecución en el Estado, con una visión generalista matizada por sus destinatarios, entendiendo que la política de bienestar se diseña en razón de necesidades sociales y también y porque no decirlo en modelos económicos y sociales, que atienden a ideologías e intereses diversos, lo que trastoca el fin último de ellas, “hacer felices a los ciudadanos". Sin embargo, pensando positivamente que estas políticas de bienestar son realmente diseñadas para lograr la felicidad de todas y todos los ciudadanos, requieren ser estabilizadas ya que su amplitud las hace laxas, inestables operativamente hablando, por lo que, en ocasión su fin no se logra en plenitud, no lo cumplen a cabalidad o se dan variables no consideradas generadas por conflictos suscitados por los usuarios o receptores de ellas por circunstancias generadas alrededor de ellas.

De igual manera surgen un sinnúmero de conflictos derivados de los intereses particulares de las personas, que son abordados y aparentemente solucionados bajo el esquema de la procuración e impartición de la justica actual, modelo que no favorece la gestión y transformación de los conflictos hasta ahora no considerados como posibles, porque la norma restringe su interpretación desde cánones previamente establecidos en la ley.

Siendo este un problema real, ya que tradicionalmente los conflictos se tratan como el incumplimiento de la norma, por lo que este se aborda desde esa perspectiva general sin considerar los intereses de cada quien, siendo este el punto de inflexión de la desestabilización de las políticas de bienestar, no generándolo.

Es entonces en este escenario en donde los MSC principalmente la mediación genera esta-

Revista Política, Globalidad y Ciudadanía, Vol. 6. No. 12, Julio - Diciembre 2020, Universidad Autónoma de Nuevo León, Monterrey, México, ISSN 2395-8448. 67-83. http://revpoliticas.uanl.mx/index.php/RPGyC/article/view/147 
bilidad desde la perspectiva del mismo bienestar considerando su percepción individual, y de forma más contundente considera la subjetividad que cada individuo le da $u$ otorga a un acto o hecho generador de situaciones o circunstancias en su vida diaria, entiéndase problemas, que desestabilizan el devenir cotidiano del estadio particular de cada quien, que de forma concéntrica interactúa con el de los demás.

Es aquí en donde se considera que la mediación atiende el bienestar subjetivo percibido, sin alterar el bienestar social en que confluimos todos, como un sistema de solución de controversias que por su método le permitirá atender intereses particulares, sin importar condición o estrato social, en un marco de interés públicos que no altera el orden público y permite a todos satisfacer sus necesidades, respetando la lógica de la convivencia en sociedad, ya que los modelos sociales actuales y sus mecanismos de control si distinguen, mientras que la mediación y los MSC no.

\section{2.- FUNDAMENTO TEÓRICO}

\section{Disrupciones que sitúan a la mediación en el contexto de las políticas de bienestar}

La mediación y los MSC cuentan ya con el rango o el nivel necesario para poder ser consideradas como una política de bienestar o como un elemento sine qua non de toda política pública de bienestar social, con un impacto de bien definido en el marco del bienestar subjetivo en lo general y en lo particular con un evidente impacto en el bienestar subjetivo percibido. Al momento histórico la mediación no se encuentra en este estadio, aún que cuenta con todo los elementos para estarlo, por diversas circunstancias de las políticas normativistas, a pesar de que ha evolucionado vertiginosamente en los últimos lustros, limitando su impacto social al actuar solo en sede judicial preponderantemente y no liberar la mediación privada, aún que las leyes lo prevén, razón de una dinámica de desconfianza, ya que el sistema de procuración e impartición de justicia limita la certificación de mediadores o facilitadores a ellos mismos, y aun así desconfian de ellos, requiriendo la supervisión y certificación del acuerdo de mediación, por ellos mismos, una redundancia irrelevante que genera la involución de la mediación privada, situación que se puede observar en todos las leyes que regulan los MSC en México (Gorjón Gómez F. J., 2018).

Sin embargo, hay disrupciones que nos permiten considerar y prever de lege ferenda que es posible la conversión de la mediación y de los MSC de constructo jurisdiccional a constructo de bienestar, por lo que estamos en presencia de un nuevo paradigma que condicionara el accionar de la mediación en donde la mediación es una metodología que genera felicidad y paz y no solo gestiona y transforma conflictos.

La primera de ellas es que la mediación y los MSC son una ciencia social emergente, hemos categorizado las razones por las cuales afirmamos esto (Gorjón Gómez F. J., 2015). La me- 
diación y los MSC cuentan con sus propias teorías, modelos y prácticas que le han permitido generar técnicas propias y estructurada por sus propios arquetipos, con un alto nivel de análisis derivado de una práctica nutrida con resultados contundentes y de un respaldo normativo y doctrinal multidisciplinar y multidimensional.

Segunda, la mediación puede ser considerada una profesión por ser producto de una necesidad social, con una metodología propia, con adaptabilidad sistémica (tipología conflictual), se sustenta en realidades, saberes auténticos y desarrolla habilidades y competencias específicas al igual de tener un impacto bien definido, armonizar las relaciones humanas y genera paz, teniendo como característica principal la participación ciudadana.

En ambos casos tanto como ciencia social emergente o como profesión, nos permite vislumbrar que la mediación es más que un simple procedimiento, que goza de elementos suficientes para proporcionar bienestar a la sociedad como cualquier otra ciencia, lo que le permitirá transitar a un sistema de bienestar.

Tercera la mediación y los MSC son generadores de felicidad y paz a través del acuerdo de mediación, como principales valores intangibles (Gorjón Gómez F. J., 2017), que al ser vistos desde una óptica positiva los hace valiosos y operativos del bienestar subjetivo percibido, resolviendo entonces los conflictos desde el interés da cada persona, la felicidad es un sinónimo de bienestar, que a su vez se desdobla en el intangible de la paz, que de forma simbiótica ambos felicidad y paz generan calidad de vida, esto es vivir bien, es el buen vivir que cada quien necesita, fundamento primigenio del bienestar (García Álvarez, 2016), el quid de esto es resolver los conflictos de las personas en razón de sus intereses, que da paso al buen vivir.

Cuarta, la progresividad de la mediación ha desencadenado a la mediación al grado de ya no considerase alterna, es cierto que las leyes la califican aún como alterna por la deficiencia evolutiva de las leyes, por su actuar lineal, que evidencia el común retraso del derecho a las nuevas metodologías de construcción social, pero, no ante este hecho debemos aceptarlo, ya que operativamente y procesalmente hablando es ya la primera opción, el reto aquí, es que no solo se signifique como una etapa procesal respaldada por el principio del debido proceso, sino por una necesidad social, ubicada en la genética social, en donde las personas recurran a ella de manera natural como suelen hacerlo cuando de su salud se trata o de su educación.

Gráfico 1. Disrupciones que sitúan a la mediación como política de bienestar.
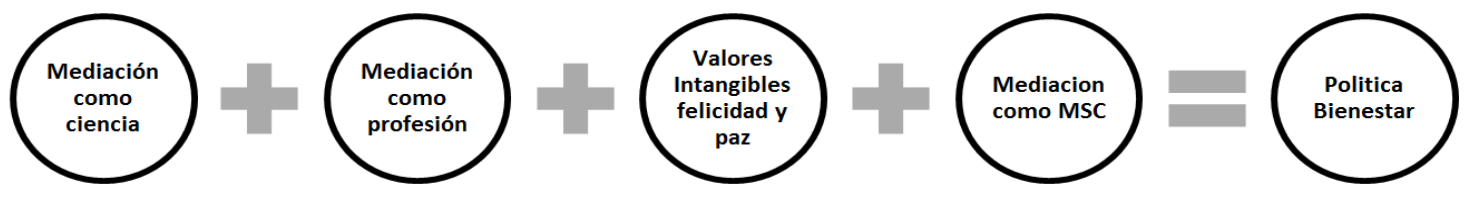

Fuente: Elaboración propia,2020

Revista Política, Globalidad y Ciudadanía, Vol. 6. No. 12, Julio - Diciembre 2020, Universidad Autónoma de Nuevo León, Monterrey, México, ISSN 2395-8448. 67-83. http://revpoliticas.uanl.mx/index.php/RPGyC/article/view/147 
Secuencia del bienestar, la mediación y los MSC

Este apartado esclarece nuestra postura de la necesidad de situar a la mediación y a los MSC en el contexto de las políticas de bienestar y desprenderla de las políticas normativista, entendiendo que una política publica son los proyectos/actividades que un Estado diseña y gestiona a través de un gobierno y una administración pública con fines de satisfacer las necesidades de una sociedad (Adelantado \& Ubasart-González, 2018) y una política normativista es aquella que se construye como un marco de legalidad, en razón de un estado de derecho que por lo regular es rígido e inflexible, ambos tienen vocaciones diferentes, el primero procura el bienestar en un amplio espectro considerando los intereses de las personas, el segundo limita los propios intereses de las personas en razón de reglas generales previamente diseñadas (Barragán, 1994).

Debo de aclarar antes de continuar, que mi postura no es radical en cuanto a desprenderla de la norma, ya que ello es materialmente imposible, toda política tiene un sustento legal, por lo que me apego a este principio para descontextualizarla, mas no cercenarla, gozando con ello de su legalidad y del amplio beneficio de sus intangibles principalmente los de la legalidad, la felicidad y la paz.

Para lograrlo es imperioso ubicarnos en un nuevo paradigma evolutivo de los MSC, por lo que es preciso transitar del paradigma de "Resolver nosotros mismos nuestros conflictos" que nos ha permitido franquear de la simple instrumentalización a la profesionalización y cientificidad, a pasar a otro nivel en el que el paradigma “los MSC son generadores de bienestar y paz”, permitirá entonces su culturización e impacto social real.

Varios son mis argumentum que nos sitúan en este nuevo contexto en razón de una secuencia lógica de la gestión y transformación de los conflictos y su combinación con los elementos esenciales del bienestar.

Debemos observar en primera instancia que bienestar es sinónimo de felicidad, por lo que, en una lógica inversa, felicidad significa bienestar. Esto a su vez nos lleva a observar esta felicidad desde la postura particular de cada quien, una cuestión evidentemente subjetiva y que se le otorga un valor particular, en razón de la percepción de cada quien, siendo este esquema como hasta ahora se han entendido las políticas de bienestar, sin embargo, estas políticas aun que son muy recurrentes por no decir que siempre están presentes en los diversos sistemas político - jurídicos en la era contemporánea, carecen de un sistema estabilizador que permita a cada individuo seguir gozando de ella, aunque existan conflictos generales, ante su incumplimiento, o ante el surgimiento de conflictos entre sus receptores, lo que impide su correcta ejecutabilidad.

Ante este escenario vinculamos en un mismo flujo la gestión moderna de los intereses de las partes, evidentemente particulares, más, sin embargo, limitados a los intereses de los demás, respetando el funcionar de las relaciones concéntricas sociales, esto es, limitando los intereses 
en relación del interés del otro.

Para lograr que esta secuencia no se interrumpa y fluya de una manera correcta, es necesario que ante el surgimiento de un conflicto que alterara esta cadena, es necesario gestionar el conflicto a través de un tercero, de un mediador, que su misión principal es asistir la negociación del conflicto y ser un representante de la realidad, situando a las partes en sus intereses y no es sus posiciones para que puedan resolver su problema, a través de un procedimiento de mediación, que concluirá en un acuerdo con un valor intangible para las partes que generara felicidad.

Este acuerdo permitirá a las partes poder continuar con su relación, y más allá, fortaleciéndola, generando lasos de fidelidad entre ellos, y como consecuencia nos sitúa en plenitud en el vivir bien, el buen vivir (VB/BV) en un esquema de reciprocidad (Schavelzon, 2015).

Gráfico 2. Secuencia del bienestar y la mediación.

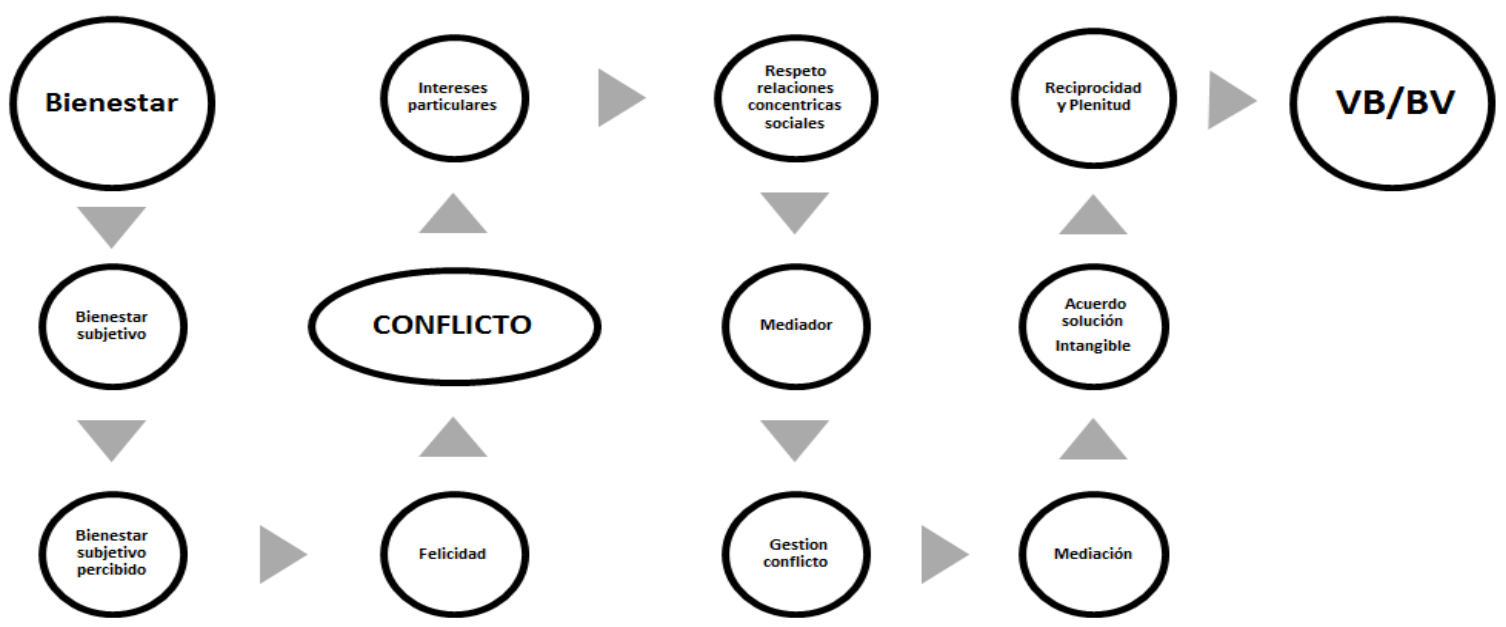

Fuente: Elaboración propia, 2020

De lo anterior surge una pregunta ¿cuáles son los elementos del bienestar que inciden directamente en la mediación?, o mejor aún ¿cuáles son los elementos de la mediación que inciden en el bienestar?

Calidad de vida (VB/BV)

Garantía (Elementos que el Estado proporciona para poder decidir, esto es el estado de derecho, la tutela del estado a los MSC)

Libertad (Capacidad de decidir)

Satisfacción (Solución del conflicto)

Habilidades sociales para relacionarse 


\section{Bienestar Subjetivo Percibido}

El bienestar subjetivo percibido (BSP) es un concepto que tradicionalmente se le ha situado en las ciencias económicas (Membiela Pollán, 2016), vinculándolo directamente al concepto de la felicidad como un sinónimo y un esquema de medición de la calidad de vida de las personas.

El BSP es una satisfacción asociada a la capacidad de elegir de las personas, pero sobre todo a la calidad del resultado que esta elección produce, así como su intensidad, que se traduce a la permanencia en el tiempo como una experiencia retrospectiva que incrementa las sensaciones positivas de nuestras acciones y de nuestro actuar en sociedad principalmente en nuestra salud y en nuestras relaciones con la familia, el trabajo y los amigos.

Gráfico 3. Accionar del BSP en la sociedad.

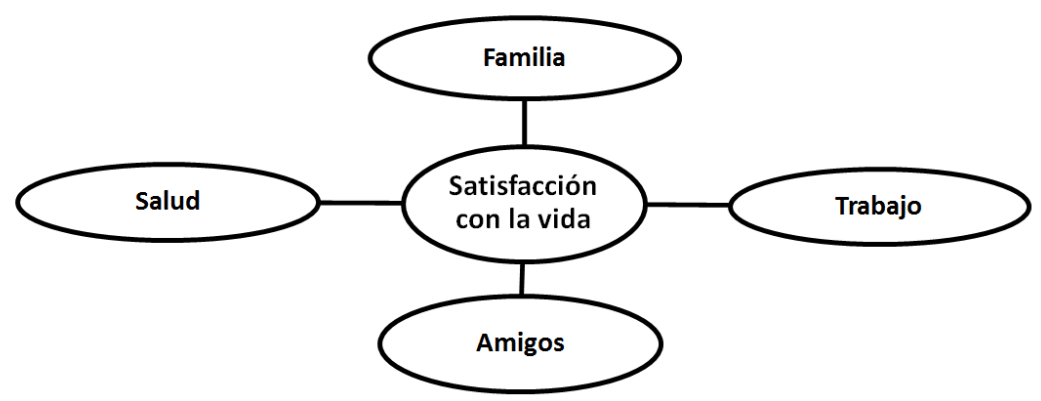

Fuente: Elaboración propia, 2020.

De igual manera es considerado el bienestar como una misión del Estado, como una política pública que orienta el accionar del Estado Moderno como un elemento crucial sine qua non de la política y los gobernantes (Vazquez, 2009) que conforma el estado de bienestar. En razón de ello "el Estado debe de proteger y cuidar a sus ciudadanos y por extensión a su sociedad en su conjunto debe de orientar su actividad a dotarla del mayor bienestar posible" (Vazquez, 2009).

Esta acción es posible en el marco del bienestar emocional y en el bienestar social como parte importante del bienestar subjetivo percibido. En relación al primero podríamos decir que este implica la búsqueda de la felicidad, al ser algo personal, interno y por lo tanto subjetivo, para percibirlo se requiere de experimentar emociones positivas, esto es, la valoración de la satisfacción de nuestra vida, de nuestra calidad de vida (Bisquerra Alzina, 2013) que implica analizar diversos factores externos, como son los ingresos, salud, vivienda, acceso a recursos, infraestructura, seguridad, bienes materiales, educación, diversión, cultura, etc.

Es en este escenario en donde los MSC intervienen como un generador de bienestar, ya que, ante la existencia de un conflicto, este perturba la armonía y nuestra calidad de vida, en consecuencia, afecta nuestro bienestar. Los MSC generaran entonces un balance en su interactuar 
social, entendiendo que el bienestar subjetivo se asocia al "grado en que un individuo juzga favorablemente la satisfacción global con la vida que lleva" (Bisquerra Alzina, 2013), por lo que desestabilizarla ante la existencia de un conflicto le impide gozar plenamente de ella.

Esta postura la confirmamos cuando analizamos el bienestar social, que tiene como rasgo esencial las relaciones de la persona con su entorno social, ya que las relaciones sociales son una fuente importante de satisfacción, pero al mismo tiempo son una fuente de conflicto (Bisquerra Alzina, 2013), por lo que concluye nuestro autor que "las relaciones son al mismo tiempo un factor de bienestar y de malestar".

Al respecto afirma que "nuestro bienestar depende del afecto y aprobación de los demás. Si a nuestro alrededor se respira ternura, comprensión, amor, entusiasmo, etc., nos va afectar positivamente. Si por nuestra parte aportamos un clima emocional positivo, aportamos bienestar social que va a repercutir en nuestro propio bienestar: se produce el efecto bumerang que hace que recibamos afecto positivo como feedback. La persona que ha aprendido las habilidades sociales para relacionarse de forma satisfactoria con otras personas mejorara su calidad de vida y su bienestar emocional".

La visión plasmada en este último párrafo centra a la persona como la responsable de lograr su calidad de vida a través de habilidades sociales, entendidas estas como competencias básicas de vida, hacen que las personas se sientan bien con quienes los rodean y tiene una percepción de bienestar que coincide con el bienestar emocional. "La satisfacción en las relaciones sociales es un factor que se correlaciona significativamente con el bienestar subjetivo" (Bisquerra Alzina, 2013), por lo que podemos deducir que este es el QUID del vínculo entre bienestar y los MSC, al considerar la gestión de los conflictos una competencia básica de vida, ya que, si la sociedad entiende que tiene la opción de resolver sus conflictos por sí mismas, su calidad de vida mejorara o aumentará y en consecuencia producirá bienestar. Entendiendo de igual manera que los MSC son una habilidad social que nos permite relacionarnos efectiva y afectivamente gestionando y transformando nuestros conflictos.

Esto lo reconfirmamos cuando vemos como área de oportunidad la conformación de las dimensiones del bienestar social (interpersonales, comunitaria y política) para la instrumentalización de los MSC ante la presencia de un conflicto.

Los factores que determinan la dimensión interpersonal son: las relaciones sociales, intimas, familia nuclear, competencias sociales y emocionales, contribución social, integración social, valores; en el caso de la dimensión comunitaria observamos el clima emocional, estabilidad familiar, solidaridad, actitudes de ayuda mutua, civismo, cortesías, comunicación, cooperación, ausencia de violencia; y para la dimensión política los factores que la definen son: la justicia, la libertad, paz, democracia, derechos humanos, estabilidad política, seguridad ciudadana, no dis- 
criminación, igualdad de oportunidades, igualdad ante la ley, equidad (Bisquerra Alzina, 2013).

En este escenario visualizamos que el conflicto es el principal elemento que puede desestabilizar las dimensiones del bienestar social y en consecuencia impedir que este logre su fin, la felicidad y la calidad de vida de los ciudadanos.

Más aún si entendemos que la percepción puede potenciar un ambiente positivo o un ambiente negativo, ya que la percepción es la capacidad de una persona de entender el mundo, es la capacidad de interpretar la información respecto a su entorno, son los estímulos que reciben sus sentidos, la percepción es el valor que le damos a la vida en razón a lo que tenemos y nos interesa, es el valor que le damos al acto, al hecho, a la acción u omisión respecto de nuestra vida en sociedad, como un proceso de selección que nos permite organizarnos en un ambiente armónico, en donde podemos afirmar que nuestra vida es buena o mala.

Es por ello que ante la ausencia de mecanismos para asegurar el cumplimiento de las políticas públicas de bienestar debe de incluirse la instrumentalización de los MSC, como un esquema de aseguramiento del bienestar subjetivo percibido, con una participación directa de las personas en la gestión y transformación de sus conflictos, ya que el conflicto afecta los intereses de las personas pero principalmente su percepción de vida, en sus diferentes roles en la operacionalización habitual de las dimensiones del bienestar social, impactando de manera directa en su devenir cotidiano, generando un efecto multiplicador de felicidad o de infelicidad (Bonete Perales, 2015).

\section{Felicidad}

Para poder entender lo que significa vivir en paz, vivir felices, debemos asociar la felicidad al bienestar, al VB/BV y a la solución de los conflictos (MSC), entendiéndola como una necesidad humana, al grado que el ser feliz puede compararse al estar sano o al amor; tiene que alimentarse y cuidarse permanentemente, no es algo que se dé por única vez y así permanezca, se requiere de mantenimiento, se requiere de cuidados, se requiere de un esfuerzo personal, porque "la mera ausencia de este esfuerzo le quitara a la vida el ingrediente imprescindible de la felicidad” (Rusell, 2018), por lo que es más fácil ser infeliz que feliz.

Podría decirse entonces, que este esfuerzo se traduce en una negociación continua, perene en el tiempo, que permita que todos aquellos elementos que se conjugan para obtenerlo estén en constante armonía y para ello es necesario que cualquier hecho, acción o acontecimiento que interrumpa nuestras sensaciones positivas, tratarlas o resolverlas, por lo que si no lo hacemos, evitara el manar del flujo de la felicidad (Csikszentmihalyi, 2016) y en consecuencia se alterara y afectara nuestro bienestar, disminuyéndolo por no lograr alcanzar nuestros intereses.

Para que este flujo sea continúo se requiere que sea dinámico, de determinadas habilidades 
para que esté vigente, habilidades en este caso, sociales como la gestión de conflictos, que hace de él, su conversión de una barrera a una oportunidad. Podemos decir entonces que los MSC son un puente, que, al gestionar y transformar el conflicto, permite que nuestra energía fluya, en pro de nuestra felicidad y bienestar, significa que nos sintamos fuertes y eficaces, alertas y con control, por lo que la clave para que este flujo continúe es necesario establecer un equilibrio entre habilidades y desafíos, por lo que “... tu felicidad depende de la capacidad de encontrar el espacio perfecto, para fluir con lo que hagas" (Lyubomirsky, 2008) y los MSC representan ese equilibrio.

La Psicología positiva es quien más ha estudiado la felicidad y el bienestar subjetivo determinando que ambos se refirieren a sensaciones positivas como la alegría o la serenidad y a estados positivos de las personas que influyen en su actuar cotidiano, pero más aún en sus acciones futuras, entendiendo que el hecho, acto o circunstancia que genera actitudes negativas, que bien podríamos catalogarlas como infelicidad, traerá consecuencias, impactando en el optimismo, la esperanza, la seguridad, la fe y la confianza (Carr, 2007).

Si analizamos las bases de un conflicto, tiene que ver con la percepción que una persona tiene de un acto o hecho, que afecta sus necesidades, su realidad y en consecuencia a sus intereses, generando el problema, ante la ausencia del logro o cumplimiento de sus objetivos, entiéndase estos como sus intereses, interrumpiendo sensaciones positivas, interrumpiendo el flujo que nosotros le hemos dado a nuestra vida, que salve decir es diferente al de los demás.

Asociando entonces la afectación de los intereses personales de los ciudadanos y la interrupción de esas sensaciones positivas a la infelicidad, generando actitudes negativas y conflictos, por lo que nuestro actuar afectara el de los demás, de ahí la necesidad de gestionar y transformar el conflicto y evitar consecuencias futuras, situándonos en nuestra realidad y en nuestra felicidad, que por consecuencia influye en nuestro bienestar.

Nuestra capacidad de decidir es lo que nos hace felices, por lo que cuando esa capacidad se ve interrumpida o cuartada somos infelices, escoger lo que nos hace sentir bien es la clave de la felicidad. Es entonces la capacidad de decidir o bien la libertad y el libre albedrio lo que correlaciona los MSC con la felicidad y el bienestar en un mismo estadio, es a través de la capacidad y de la libertad la manera de materializar la felicidad, al ser medible podemos definir qué tan felices somos, a diferencia del bienestar ya que según (Seligman, 2014) este es considerado un constructo, "que tiene a su vez, varios elementos mensurables, porque cada uno de ellos es una cosa real y cada uno contribuye al bienestar".

Uno de estos elementos es la felicidad misma, esas sensaciones positivas que nos permiten reaccionar positivamente con los demás y se convierte en un circulo virtuoso, a diferencia del bienestar que se ve condicionado a otros elementos o factores que implican el vivir bien o buen 
vivir, en donde se requieren de otros factores, como los señalamos en apartado anterior, sin embargo, estos al no verse materializados o que cumplan su misión, son generadores también de conflictos y es en este momento "reitero" en donde la intervención de los MSC hacen posible el bienestar y la felicidad, como un binomio de vida que difícilmente puede ignorarse.

Ahora bien, que significa vivir bien o buen vivir (VB/BV) y porque lo vinculamos al bienestar y la felicidad, tiene que ver con nuestra conducta y con nuestra actuar con los demás, significa que lo que hagamos o dejemos de hacer afecta a quienes nos rodean, significa que lo que uno es o lo que uno representa individualmente trasciende (Schopenhauer, 2017), nuestra individualidad es nuestra fuerza, vivimos en una sociedad que se compone de individualidades, pero estas a su vez se suman en un mismo acontecer, a un mismo fin, que hace de las sociedades sean coherentes, cuando esas individualidades se dispersan, el flujo se interrumpe y el VB/BV pasa de ser una estadio de oportunidad a un estadio de infelicidad.

$\mathrm{VB} / \mathrm{BV}$ significa convivir dignamente lo que implica desarrollar capacidades humanas para lógralo (habilidades sociales de gestión de conflictos), implica la construcción de condiciones sociales adecuadas para una real apropiación de los medios de producción, que hacen que una sociedad funcione, implica también equilibrio para lograr autonomía, justicia e igualdad (Contreras Baspineiro, 2016).

$\mathrm{Al}$ respecto nuestro autor vincula el VB/BV a la armonía, como una cosmovisión, entiéndase esta como "una forma de ver, de interpretar, de construir el mundo con un conjunto de creencias y convicciones que nos permiten analizar, interpretar y reconocer la realidad en que vivimos".

Entiéndase que lo que se pretende es reivindicar el valor primordial de la vida y para lograrlo es necesario vivir en convivencia, vivir dignamente y vivir plenamente. Este último axioma es tal vez el de mayor peso en cuanto a nuestro propósito de la gestión y transformación del conflicto, ya que determina que "la felicidad de uno es la felicidad de todos, con relaciones de colaboración, sin ostentaciones, con lo suficiente, sin discriminaciones, con justicia” (Contreras Baspineiro, 2016).

Para lograr que el VB/BV se logre en plenitud es necesario forjar una cultura de vida, una cultura de armonía y esta solo será posible si se logra construir y conciliar las siguientes relaciones según (Contreras Baspineiro, 2016) :

1. La armonía de los seres humanos consigo mismos. Esta es la dimensión subjetiva y espiritual del VB/BV. Implica trabajar nuestros sentimientos para trabajar por una vida digna en igualdad de condiciones entre hombres y mujeres, en solidaridad y suficiencia, y

2. La armonía de los seres humanos en sociedad. Esta es la dimensión comunitaria que implica vivir colaborativamente, relacionándonos, respetándonos, apoyándonos, traba- 
jando en comunidad, en justicia.

Ahora bien, para que todo esto mantenga su status quo es necesario que observemos dos elementos más del VB/BV que es la integralidad y el equilibrio (Contreras Baspineiro, 2016). La integralidad es el sentido comunitario de la vida, es una identidad colectiva que tiene en la convivencia solidaria el espacio para satisfacer las necesidades (intereses mas no posiciones). Es una exigencia normativa que permite una vida fraterna, una vida en convivencia y armonía que basa su accionar en los valores de la igualdad, la diversidad, la equidad, el bien común, la transparencia y la ética.

Ahora bien, el equilibrio tiene el mismo sentido de lograr una vida fraternal y en armonía, entendiéndolo como una balanza de los intereses de los individuos en donde el dintel de esa balanza es el bienestar y sus extensiones son la convivencia solidaria y amistosa, que permite construir alternativas desde practicas basadas en la justicia y en la equidad.

Entendemos entonces, que el factor que sincroniza todos estos conceptos es la convivencia, una convivencia en armonía, justa y equitativa, es entonces, la necesaria integración de los MSC a las diversas ecuaciones que integran el VB/BV, ya que sin un proceso de gestión de conflictos que evite la desarmonización de esta convivencia, evidentemente no se lograra el bienestar, en nuestra más amplia concepción de felicidad.

\section{Escenario de culturización cuando proponemos la implementación de los MSC}

Las dinámicas en las que las políticas públicas integran a la sociedad responden a las características mismas por las que fueron creadas, entiéndase como el fin que persiguen, el presente apartado identifica el escenario es donde se desarrollaría la culturización de los MSC y de cómo actualmente estas dinámicas condicionan el actuar social en cuanto a la procuración e impartición de justicia y de los MSC desde dos perspectivas: lineal y exponencial; la actual que sitúa a la mediación en el normativizo (lineal) y la prospectiva que situaría a la mediación como política de bienestar (exponencial) que permitirá su evolución en razón de los elementos operativos que aplican a otras políticas como lo es la educación o la salud por mencionar alguna en donde su espectro es multidimensional y de superior alcance impactando a toda la sociedad y no solo a un sector determinado. 
Cuadro 1. Normativismo vs Bienestar

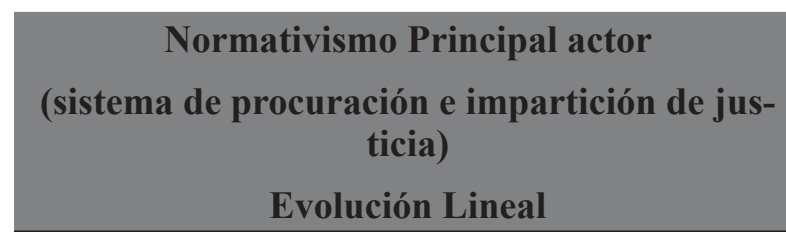

1. Paz negativa

2. Poder que genera autodefensa y protagonismo

3. Instrumenta la política pública, es el garante de la cohesión y justicia social y garantiza un estado de derecho

4. Obliga a la sociedad a cumplirla

5. Dinámica individualista ante la pérdida de control

6. La ley limita el accionar de las personas

7. Salvaguarda los intereses de la sociedad según la norma

8. Limitada a los abogados y algunas ciencias auxiliares

9. Los cambios de las normas son complejos y lentos

10. Limita los cambios sociales

\section{Bienestar Subjetivo Principales actores}

(demás sistemas gubernamentales)

Evolución exponencial
1. Paz positiva

2. Responsabilidad compartida búsqueda apertura

3. Instrumenta la política pública como un deber privilegiando los intereses particulares y sociales

4. Calidad de vida

5. Comparte la responsabilidad (trabajo en equipo, acciones intergubernamentales)

6. Las políticas públicas alienta la cooperación y generan sinergias

7. Privilegia los intereses de las personas, promueve la libertad y la identidad social

8. Es multidisciplinar

9. Es dinámica, se adapta, genera apertura y máximos beneficios

10. Gesta cambios sociales

Fuente: Elaboración propia, 2020.

\section{Beneficios de los MSC en el Bienestar subjetivo vs Normativismo}

Confrontar las dinámicas de ambos escenarios es conveniente para entender las ventajas que el bienestar ofrece vs el normativismo en la evolución de la mediación. De forma particular destacamos los efectos sobre los usuarios cuando resolvemos el conflicto desde la perspectiva del normativismo, que refleja nuestra realidad, y cuál es su efecto. Cuando lo situamos en el bienestar la dinámica cambia y el flujo es diferente, y aún que esto sucede y que no es una suposición, mantenemos los MSC en el normativismo, por lo que produce una implosión que pide a gritos su tránsito al bienestar, ya que la lógica de su operacionalización es diferente, ya que mientras el normativismo es general y trata al conflicto desde el incumplimiento de la norma, la gestión y transformación del conflicto es abordado desde la impronta del bienestar ubicando el conflicto desde la perspectiva del interés de las personas de forma particular.

Presentamos entonces ambos escenarios en razón de sus rasgos distintivos ya no solo como política generalista sino como resultado de su instrumentalización y lo que implicaría situar a 
los MSC dentro del halo del bienestar, pretendiendo con ello convencer al lector de forma razonable de como uno suscita más opciones y mejores oportunidades en relación al otro en cuanto a la gestión y transformación del conflicto y a la perdurabilidad de sus resultado, derivado de la experiencia de otras políticas públicas de bienestar que se centran en las personas y no solo en la norma.

Cuadro 2. Los MSC en el normativismo y en el Bienestar

\begin{tabular}{|c|c|}
\hline $\begin{array}{l}\text { Los MSC en la política normativista } \\
\text { Rasgos distintivos que condicionan sus } \\
\text { beneficios }\end{array}$ & $\begin{array}{l}\text { Los MSC en la política de bienestar } \\
\text { Rasgos distintivos que condicionan sus } \\
\text { beneficios }\end{array}$ \\
\hline $\begin{array}{l}\text { 1. La norma es de aplicación general, no se cen- } \\
\text { tra en el interés de las personas } \\
\text { 2. La norma es rígida e inflexible } \\
\text { 3. El conflicto se aborda desde el incumpli- } \\
\text { miento de la norma } \\
\text { 4. Desconfianza } \\
\text { 5. Insatisfacción del resultado } \\
\text { 6. La Norma no es perceptible por las partes } \\
\text { 7. La norma mantiene el status quo de las per- } \\
\text { 8. La norma no es positiva ni negativa, es ge- } \\
\text { neral } \\
\text { 9. La norma no es entendible por la sociedad } \\
\text { 10. La sociedad vive }\end{array}$ & $\begin{array}{l}\text { 1. El bienestar puede tener diversos destinata- } \\
\text { rios, se centra en las personas y en sus inte- } \\
\text { reses } \\
\text { 2. El bienestar es flexible } \\
\text { 3. En el bienestar el conflicto se aborda desde el } \\
\text { interés de las personas } \\
\text { 4. Confianza } \\
\text { 5. Satisfacción } \\
\text { 6. Su percepción es su mayor fuerza } \\
\text { 7. El bienestar gesta cambios particulares y so- } \\
\text { ciales } \\
\text { 8. El bienestar es positivo privilegia la satisfac- } \\
\text { ción y las emociones, la felicidad } \\
\text { 9. Es de fácil comprensión y adaptación } \\
\text { 10. Convence a la sociedad de vivir bien, del } \\
\text { buen vivir }\end{array}$ \\
\hline
\end{tabular}

Fuente: Elaboración Propia, 2020.

\section{3.- MÉTODO}

La propuesta metodológica de la presente investigación tiene un ámbito multidimensional, que pretende abordar diversos elementos conceptuales operativos en donde la mediación asumiría un rango de política de bienestar.

La investigación deberá fijar una postura teórico práctica de cada concepto operativo y/o de influencia vinculado a los métodos de solución de conflictos y al bienestar, al bienestar subjetivo, al bienestar subjetivo percibido y a la felicidad como producto del acuerdo de mediación y el impacto que este generará en la sociedad, como, por ejemplo, la concertación, el perdón, o 
la felicidad.

Para determinar los diversos vocablos operativos de los métodos de solución de conflictos y del bienestar deberá observase literatura especifica en el tema de los MSC, del bienestar, de la felicidad y la paz, así como autores especialistas en el tema, considerando de igual manera los diversos instrumentos legales o rectores como planes de acción, convenciones o declaración vinculados, así como las mejores prácticas para la disminución de la violencia estructural, la generación de bienestar subjetivo percibido y la paz estructural.

Utilizaremos el método analítico sintético, empírico y exegético partiendo de la experiencia del autor en los diversos métodos y de la experiencia para la elaboración y clasificación de los vocablos operativos de los MSC y del bienestar que inciden en su instrumentalización.

\section{4.- CONCLUSIONES}

La mediación genera estabilidad en las relaciones particulares, por lo que es imprescindible situarla en el escenario global social a través del bienestar.

La felicidad y el bienestar dependen de una vida en comunidad, por lo que el conflicto los desequilibra.

La vida en sociedad se caracteriza por las decisiones individuales que afectan a los demás, por lo que el bienestar y la felicidad dependen de esas decisiones individuales.

El bienestar y la felicidad no tiene un sistema que involucre a las personas para sostener su estabilidad por lo que requiere de un método para lograrlo.

La mediación y los MSC son una metodología que genera y estabiliza la felicidad y la paz, a través del acuerdo, como un valor intangible.

La mediación generaría estabilidad de los factores de las políticas públicas de bienestar, estabilizando las decisiones particulares de las personas, ante un eventual conflicto.

Es factible invertir la lógica de la generación del bienestar, otorgándoles un papel protagónico a las personas para su operación y estabilidad.

Los MSC debemos situarlos en el constructo del bienestar como base sustancial e interactuar solo normativamente en el constructo de la normativización.

El resultado de la mediación y de los MSC se correlaciona directamente al bienestar subjetivo percibido, ya que el conflicto se aborda desde los intereses de las partes.

La mediación al igual que el bienestar produce felicidad, armonía y paz.

Es necesario situar a los MSC en las políticas de bienestar para poder evolucionar exponencialmente y generar una verdadera culturización. 


\section{REFERENCIAS}

Adelantado, J., \& Ubasart-González, G. (2018). ¿Que es el Estado de Bienestar? En F. E. Cammas Roda, manual del esatdo de BIenestar y las Políticas Laborales (págs. 31 - 44). Barcelona: Huygens.

Barragán, J. (1994). Como se hacen las leyes. Madrid: Planeta.

Bisquerra Alzina, R. (2013). Cuestiones sobre bienestar. Madrid: Sintesis.

Bonete Perales, E. (2015). Tras la felicidad Moral. Madrid: Catedra.

Carr, A. (2007). Psicología positiva. la ciencia de la felicidad. Barcelona: Paidos.

Contreras Baspineiro, A. (2016). La palabra que camina. Comunicación popular para vivir bien/buen vivr. Ecuador: Ciespal.

Csikszentmihalyi, M. (2016). Fluir (Flow). Una psicologia de la felicidad. Barcelona: kairos.

García Álvarez, S. (2016). Sumak Kawsay o Buen Vivir como alternativa al desarrollo del Ecuador. Quito: Abya-Yala.

Gorjón Gómez, F. J. (2015). De la instrumentalización a la cientificidad de la mediación y de los métodos alternos de solución de conflictos. En F. Gorjón, \& J. Pesqueira, La ciencia de la mediación (págs. 13 - 35). México: Tirant Lo Blanch.

Gorjon Gómez, F. J. (2015). Teoria de la Impetración de la Justicia. Por la necesaria ciudadanización de la justicia y la paz. Comunitania, 113 - 131.

Gorjón Gómez, F. J. (2017). Mediación, su valor intangible y efectos operativos. Una visión integradora de los Métodos Alternos de Solución de Conflictos. México: Tirant lo Blanch.

Gorjón Gómez, F. J. (2018). Manual de mediación penal, civl, familiar y justicia restaurativa. Para mediadores, facilitadores e intructores. Guía práctiva para capacitación y certificación. México: Tirant Lo Blanch.

Lyubomirsky, S. (2008). La ciencia de la felicidad. Un metodo probado para conseguir el bienestar. Barceloina: Urano.

Membiela Pollán, M. (2016). La Teoria del Capital Social. Coruña: Camiño Do faro.

Rusell, B. (2018). La conquista de la felicidad. México: Gandhi.

Schavelzon, S. (2015). Plurinacionalidady Vivir Bien/Buen Vivir. Quito: Abya Yala/Clacso.

Schopenhauer, A. (2017). Sobre el buen vivir. Consejos para ser feliz. México: Gandhi. 
Seligman, M. E. (2014). Florecer- La nueva Psicologia positiva y la busqueda del bienestar. Madrid: Oceano.

Vazquez, C. (2009). El Bienestar de las Naciones. En C. E. Vazquez, la ciencia del Bienestar (págs. 103 - 137). Madrid: Alianza. 